\title{
A esportivização das políticas sociais no sul do RS: discursos e blasfêmias
}

\author{
La esportivização de políticas sociales em el sur de RS: discursos e \\ blasfemia
}

\section{The sportification of social policies in southern RS: speeches and blasphemies}

\author{
Mauricio Cravo dos Reis ${ }^{1}$ \\ Méri Rosane Santos da Silva ${ }^{2}$
}

\begin{abstract}
Resumo
Este artigo aborda a temática da esportivização das políticas sociais na região sul do Rio Grande do Sul, mapeando os projetos sociais esportivos existentes e após analisando narrativas recorrentes da prática oriunda dessas políticas. Pautado numa perspectiva pós-estruturalista, o estudo caracteriza-se como qualitativo, na qual utiliza-se de documentos oficiais e como instrumento de produção de dados a entrevista semiestruturada, realizada com proponentes de projetos sociais esportivos de nove munícipios pertencentes a região. Entre os discursos enfatizados pelos proponentes, pode-se destacar a utilização do esporte como meio para salvação dos sujeitos, distanciamento da violência e das drogas, ocupação do tempo ocioso e por último, a complementação à educação física escolar. Diante de tal cenário, foi possível perceber que tais políticas, regulam, controlam e normalizam os sujeitos delas participantes, caracterizando novos modos de vida, diferentes formas de ser e estar inserido na sociedade.
\end{abstract}

Palavras-Chave: discursos; esporte; políticas sociais;

\section{Resumen}

Este artículo aborda la cuestión de la esportivização de políticas sociales en la región sur de Rio Grande do Sul, la asignación de los proyectos sociales existentes de deportes y después de analizar los discursos de los candidatos a la práctica de estas políticas. Basado en una perspectiva postestructuralista, el estudio se caracteriza como un salto cualitativo, en el que se utiliza en documentos oficiales y como instrumento de producción de datos una entrevista semi estructurada con los proponentes de proyectos sociales de nueve munícipios deportivos pertenecientes a la región. Entre los discursos han puesto de relieve por los proponentes, podemos destacar la utilización del deporte como medio para la salvación del sujeto, liberado de la violencia y las drogas, la ocupación de tiempo de inactividad y, finalmente, para complementar la educación física en la escuela. Ante este escenario, es posible darse cuenta de que tales políticas visam, regular, controlar y normalizar el tema de ellos participantes, caracterizar las nuevas formas de vida, diferentes maneras de ser y de insertarse en la sociedade.

Palabras claves: discursos; desporte; políticas sociales;

\footnotetext{
Abstract

1 Mestre em Educação; Universidade Federal do Rio Grande; Rio Grande, Rio Grande do Sul, Brasil; mauriciocdosreis@hotmail.com

${ }^{2}$ Doutora em Ciências do Movimento Humano; Universidade Federal do Rio Grande; Rio Grande, Rio Grande do Sul, Brasil; meri.rosane@ hotmail.com (In Memóriam)
} 
This article deals with the sportivization of social policies in the southern region of Rio Grande do Sul, mapping the existing social sport projects and after analyzing recurrent discourses of the practices originating from these policies. Based on a post-structuralist perspective, the study is characterized as qualitative, in which official documents are used and as a data-producing instrument the semi-structured interview conducted with proponents of social sports projects from nine municipalities belonging to the region. Among the speeches emphasized by the proponents, one can highlight the use of sports as a means for the salvation of the subjects, distancing oneself from violence and drugs, occupying idle time and, finally, complementing physical education at school. Faced with such a scenario, it was possible to perceive that such policies regulate, control and normalize the subjects of the participants, characterizing new ways of life, different ways of being and being inserted in society.

Keywords: discourse; sport; social policies;

\section{Engendramento Temático}

O presente artigo tem como temática central as políticas sociais vinculadas ao esporte e os efeitos de projetos sociais esportivos na região sul do Rio Grande do Sul. Parte-se do pressuposto de que a análise de políticas públicas requer que se reflita sobre a sua implementação. Dessa forma, é possível dividi-la entre sua elaboração e construção, que delimitam sua forma de gestão, consubstanciada na proposição de objetivos e impactos a serem alcançados, e os resultados obtidos pela aplicação destas políticas, ou seja, seus efeitos sociais.

Atualmente, na sociedade contemporânea, observa-se o aumento e a variedade de políticas sociais de origem pública e privada direcionadas aos projetos sociais esportivos, na qual são destinados, em sua grande maioria, a crianças e adolescentes. Esses projetos possuem como pressupostos e objetivos a inclusão social, o combate às drogas e a violência, a educação e o resgate à cidadania.

Considera-se que projeto é uma palavra que remete a mais de um significado, dependendo da forma e de quem se propõe a usar essa expressão, em geral, define-se projeto social como um conjunto de ações que buscam transformar de alguma maneira a realidade, reduzindo ou eliminando um déficit, ou solucionando um problema. (SOUZA, 2008).

De acordo com Correia (2008) projeto social de esporte trata-se de um conjunto de atividades concretas, coordenadas e inter-relacionadas, porém com orientação mais especificas e objetivadas para as soluções dos problemas identificados em um dado momento e a um determinado grupo social.

Os projetos sociais, em especial os direcionados ao esporte, ganharam força a partir dos anos de 1990 (LANDIM apud GUEDES, 2006) com o aumento de importância do chamado terceiro setor e a valorização das políticas públicas da área de esportes que atualmente são designadas para atender as necessidades das camadas menos favorecidas da 
população. Esses projetos são propostos por diversas iniciativas, dentre as quais estão mais evidentes as organizações não governamentais, organizações governamentais, as empresas privadas e as iniciativas individuais. Tal constatação indica uma nova estratégia de educação da sociedade brasileira e mundial em relação aos setores menos favorecidos da população. Em outras palavras, pode-se afirmar que nos últimos anos cresce e se fortalece as parcerias entre o setor público, privado e sociedade civil. As ações sociais promovidas por empresas, Organizações Não Governamentais, atletas e ex-atletas, buscam com a visibilidade pública, colaborar para a divulgação das ações do chamado terceiro setor. Da mesma forma, a noção de direito social é substituída pela de responsabilidade social de empresas e personalidades. É dessa forma que as empresas, ONGs e organizações governamentais têm utilizado o conceito de responsabilidade social, para vincular suas marcas às ações sociais que procuram desenvolver.

O público alvo dessas políticas sociais, normalmente se direciona a crianças, jovens e adultos que residem em bairros periféricos, e a oferta se dá, na sua grande maioria, através de práticas desportivas. Essa estratégia é justificada pelo apelo popular ao esporte por este público e principalmente pelos possíveis benefícios que essas práticas trazem para os participantes.

Além disso, a vulnerabilidade social é algo recorrente nos discursos produzidos nas ações sociais esportivas, pois o público participante é caracterizado a partir de necessidades básicas e denominado como vulneráveis sociais, na qual existe a necessidade de aprofundamento conceitual e analises teóricas. De certa forma, esse discurso é acompanhado por outros que a todo instante tentam justificar a existência desses projetos como a falta de acesso ao lazer e práticas esportivas, afastamento de possíveis riscos que existem nos ambientes onde os projetos são propostos, a ocupação do tempo ocioso das crianças e jovens, a promoção da cidadania e determinada formação moral dos participantes, todos estes fatores associados à vulnerabilidade social.

Na lógica da vulnerabilidade social (GONÇALVES, 2003 p. 172) indica que:

\begin{abstract}
"Afastar os meninos do mundo do crime, tirá-los da rua, livrá-los da violência - estas têm sido as justificativas usadas pelos projetos sociais voltados para jovens das comunidades pobres. Todos pretendem ocupá-los com atividades educativas, esportivas, culturais e de formação para o trabalho. Acreditam que o espaço deixado pela carência de atividades possa ser ocupado pelo crime ou pelo ócio. São várias as entidades espalhadas pelo país cuja intenção é tirar moças e rapazes de situação de risco".
\end{abstract}

Alinhado a estes fatos, o esporte, considerado um fenômeno sócio-histórico-cultural, tem ganhado amplitude e importância na vida das pessoas que integram a sociedade atual. No 
Brasil, as evidências dessa valorização se dão através do alto nível de expansão dos dados quantitativos dirigidos ao esporte.

Com base neste contexto, aumenta a percepção de que o esporte pode ser um instrumento fundamental no auxílio a crianças e adolescentes em situação de risco social e outras vulnerabilidades. Se para uma parcela da sociedade, esporte significa basicamente competição, tem se demonstrado através das políticas atuais que ele vai além das disputas que ocorrem nos estádios e ginásios. A cada dia, como afirmam Borges e Campos (2004), aumenta a importância do esporte como ferramenta de inclusão social.

Esses dados têm servido como justificativa para a utilização do esporte como ferramenta no oferecimento de ações sociais no Brasil. Na região sul do estado do Rio Grande do Sul, há indícios que não têm sido diferente, pois há significativas manifestações de projetos sociais esportivos espalhados pelos bairros das cidades que compõe essa região.

A região sul desse estado é composta por aproximadamente 25 (vinte e cinco) municípios, entre eles estão Amaral Ferrador, Arroio Grande, Candiota, Capão do Leão, Aceguá, Arroio do Padre, Canguçu, Cerrito, Herval, Hulha Negra, Morro Redondo, Pedras Altas, Pedro Osório, Pinheiro Machado, Piratini, Chuí, Cristal, Jaguarão, Pelotas, Rio Grande, Santa Vitória do Palmar, Santana da Boa Vista, São José do Norte, São Lourenço do Sul e Turuçu. A população total dessas cidades é de 863.956 habitantes, dos quais 151.765 vivem na área rural, o que corresponde a $17,57 \%$ do total. Esses dados foram divulgados recentemente através do Sistema de Informações Territoriais pertencente ao Governo Federal.

Essa região passou nas últimas três décadas por um declínio econômico devido ao enfraquecimento do setor industrial. Com isso a população passou a ser constituída e considerada em um estado de vulnerabilidade social, na qual as necessidades mais básicas para a sobrevivência começaram a ser negadas, porém as novas ações do governo do estado do Rio Grande do Sul e algumas iniciativas privadas estabeleceram uma espécie de recuperação da região sul do estado nos últimos anos. Com a elevação dos investimentos que a região obteve através das políticas de recuperação, foi estimulado investimentos públicos e privados associados a discursos que convocam tanto o governo, como a sociedade civil e as iniciativas populares da região a promoverem projetos sociais, em especial esportivos (MARTINS, 2002).

Mesmo que previamente, cabe indicar a existência de projetos sociais esportivos em alguns dos municípios pertencentes a região sul do estado do Rio Grande do Sul como o Projeto Segundo Tempo, Esporte e Lazer na Cidade, Escola Aberta entre outros oferecidos pelo Governo Federal através do Ministério do Esporte. A iniciativa privada também promove 
ações sociais esportivas como o Projeto Atleta do Futuro vinculado ao Serviço Social da Indústria, Centro de Referência em Esporte Educacional vinculado a Petrobras, na qual também propõe uma Rede Multiplicadora de Professores que visa fortalecer a metodologia do esporte educacional na Educação Física escolar. Além disso, sabe-se da existência de um número considerável de projetos esportivos oferecidos por ONGs e iniciativas individuais.

Independente da origem que esses projetos possuem, há uma relação entre os discursos produzidos em diferentes espaços pedagógicos que de certa forma apontam relativa insuficiência da Educação Física escolar como proponente de um espaço para amenizar riscos sociais dos alunos. Mas ao mesmo tempo, grande parte dos projetos esportivos utiliza a escola como ferramenta ou parceira para atribuir como condição de participação, o rendimento através do acompanhamento dos desempenhos ou conceitos dos alunos nas escolas que estão inseridos.

Outro fator interessante dessas ações é a expansão das áreas dos profissionais que compõe o quadro funcional dos projetos. Grande parte desses é composto por educadores físicos, fisioterapeutas, enfermeiros, assistentes sociais, psicólogos, pedagogos, entre outros. Dessa forma identifica-se o trabalho multiprofissional como forma de amenizar os diferentes déficits apresentados pela população que procura esses serviços através dos projetos esportivos.

Sendo assim, a pesquisa visou abranger a seguinte questão: Quais os efeitos da produção de discursos vinculados ao esporte na formação de sujeitos participantes de políticas sociais esportivas na região sul do Rio Grande do Sul? Dessa forma buscou-se, primeiramente, mapear os projetos sociais esportivos existentes em nove municípios da região sul do Rio Grande do Sul, identificar através da produção de narrativas os discursos existentes entre participantes dos projetos sociais esportivos nas cidades do sul do Rio Grande do Sul;

\section{Políticas sociais de esporte: discursos para além da educação}

A política pública pode ser entendida por uma intervenção na realidade, envolvendo diferentes sujeitos e, dependente de interesses e expectativas (GOMES, 2001). Dessa forma, as políticas públicas são consideradas formas de regulação e intervenção na sociedade e que também articula diferentes sujeitos. 
Além disso, as políticas sociais constituem-se de um conjunto de ações ou omissões do Estado decorrente de decisões que demonstram expectativas e interesses variados, tendo como limites e condicionamentos os processos econômicos, sociais e políticos (SILVA, 2001).

\begin{abstract}
[...] uma política pública desde a sua formação, envolve mobilização e alocação de recursos, divisão de trabalho (tempo); uso de controles (poder), interação entre sujeitos; interesses diversos, adaptações; riscos e incertezas sobre processos e resultados; noção de sucesso e fracasso, destacando-se a relevância dos sujeitos sociais desse processo e suas racionalidades (SILVA, 2001, p. 40).
\end{abstract}

Segundo Marshal (1967, p. 7), a expressão política social não é um termo técnico com um significado preciso "[...] se refere à política dos governos relacionada à ação que exerça um impacto direto sobre o bem-estar dos cidadãos, ao proporcionar-lhes serviços ou renda".

As políticas sociais têm sido traduzidas em um complexo processo de relações da sociedade com o Estado, no enfrentamento de interesses dos blocos que disputam legitimidade, poder e ganhos econômicos, cujos resultados variam em função das diferentes conjunturas históricas. Dessa maneira, a política social torna-se uma conquista participativa dependendo da influência do movimento social sobre o planejamento e execução de uma política pública (SPOSATI et. al., 1985).

Essas promoções de projetos e programas sociais oriundos de empresas privadas têm colaborado para o fortalecimento dos ideais empreendedores empresariais. Nesse contexto, a responsabilidade social, e as novas formas de organização deste setor, vêm ao encontro das questões sociais, sejam elas urbanas, rurais, do meio ambiente, gênero ou raça. Para isso, o esporte é utilizado como ferramenta fundamental para o encontro entre os projetos e programas sociais e os cidadãos considerados vulneráveis.

O modelo de esporte de caráter utilitário e funcional multivariado, encontra ressonância nos discursos que provém do eixo governamental do Brasil. Em busca no portal eletrônico do Ministério dos Esportes, por exemplo, torna-se importante para demonstrar que o esporte assume a condição de um benefício fundamental capaz de promover qualidade de vida, bem-estar e inclusão social; proteger dos perigos das ruas; ocupar o tempo livre; combater o uso de drogas; ensinar lições de disciplina e formar verdadeiros cidadãos.

A utilização de discursos em prol do esporte através de certos slogans do tipo "esporte é vida" ou "esporte é saúde" são frequentemente enunciados por parte da mídia e/ou por profissionais da área da saúde como forma de atrair adeptos e participantes. Os projetos sociais esportivos também fazem uso desses dispositivos para reforçar e alargar a importância 
que o esporte possui para as mudanças sociais necessárias. Nesse sentido, contrariar qualquer tipo de discurso que possui status de hegemônico, pode ser considerado um ato de blasfêmia.

Fraga (2000) coloca que o poder de penetração de um discurso na vida social está associado à sua capacidade de ser visto como algo natural, tornando imperceptíveis seus efeitos entre aqueles que se encontram capturados. Os documentos dos projetos sociais de esporte constam que as práticas esportivas são uma das formas de combate a vulnerabilidade social, além de ser também um direito de cada criança e adolescente.

Nesse sentido Salomão (1987, p. 185) afirma que “[...] a sociedade da mesma forma, é também um reflexo de nossa filosofia de vida. Podemos dizer de um modo geral, há uma grande influência social no esporte e deste na sociedade". E desta forma a socialização tornase um dos principais objetivos da utilização do esporte por projetos sociais. Boixadós et al. afirma que o processo de socialização relacionado ao esporte pode ser dividido em três partes:

\begin{abstract}
a - socialização para o esporte (valores, atitudes que a equipe ou a família consideram mais importantes e que produzem a atração inicial pelo esporte); b- socialização através do esporte (diz respeito a atitudes, habilidades gerais, trabalho em grupo, disciplina, esportividade, valores que podem ser obtidos através do envolvimento pessoal no esporte); c- abandono ou retirada do esporte (essa fase diz respeito aqueles que praticam ou praticavam o esporte de rendimento, de forma amadora ou profissional, mas com ênfase na competição visando aos resultados). (BOIXADÓS et al., 1998, p. 298).
\end{abstract}

Segundo Gawryszewski (2006), o lema para a legitimação das políticas públicas de esporte foi e tem sido o da promoção da cidadania e da inclusão social, como mecanismos controladores da inquietude dos jovens. É atribuído ao esporte, como afirma o autor, o desafio de salvar os adolescentes do envolvimento, uso ou o tráfico de drogas assim como outros desvios comportamentais. Nessa perspectiva o esporte é utilizado como forma de normalizar a conduta dos jovens brasileiros.

A complementaridade dos projetos sociais em relação à escola é analisada nos estudos realizados por Guedes (2006), o qual afirma que todos os projetos por ele estudados se colocam na posição de complementaridade à educação escolar formal, repetindo uma norma que se tornou consensual nestes projetos: são inscritas apenas as crianças e jovens que estiverem matriculadas na escola. Além disso, alguns projetos avaliam o desempenho dos alunos na escola como requisito básico para o ingresso e manutenção destes nas atividades. Há maior ou menor tolerância, mas em grande parte das vezes, a necessidade do bom desempenho escolar é mais verbalizada do que avaliada. 
A valorização difusa da educação e de escola, relatada em discursos como a única forma possível para minimizar as desigualdades sociais, associada a visão de uma escola pública universal de baixa qualidade, também difundida e, à ausência de políticas públicas eficazes ligadas aos esportes, criam o espaço ou até mesmo a necessidade do desenvolvimento e a proliferação dos projetos sociais esportivos.

É nesse sentido que, ao tratar as questões de esporte/educação, Machado (2007) entende que o esporte é um articulador de ações educativas, juntamente com atividades que priorizam a saúde, a arte e o apoio à escolarização. Vários projetos educativos interdisciplinares, segundo este autor, são apresentados às crianças objetivando a construção participativa, orientada nos princípios da Educação pelo Esporte.

\section{Traços metodológicos: decisões no caminho}

As pesquisas de cunho educacional possuem origem nos pressupostos da importância da descrição dos critérios e nos procedimentos ao invés de valorizar denominações ou tipologias metodológicas. Dessa forma, este artigo buscou a partir de narrativas de proponentes de projetos sociais esportivos, identificar e analisar como são produzidos discursos sobre as políticas e seus efeitos nos modos de vida dos mesmos.

Além disso, a pesquisa utilizou como apoio o referencial pós-estruturalista. Essa perspectiva revela certo descompromisso para com essências e verdades universais e, ao mesmo tempo, possibilita ao pesquisador que o toma como inspiração “(...) a construção de uma metodologia com um horizonte aberto de possibilidades (...)" (VEIGA-NETO, 2004, p.41).

Como delimitação do estudo, diante do expressivo número de municípios pertencentes a região sul, optamos pela escolha de nove municípios, sendo eles: Rio Grande, Pelotas, São José do Norte, Santa Vitória do Palmar, Chuí, Canguçu, São Lourenço do Sul, Pedro Osório e Arroio Grande. A escolha se deu, pela facilitação de contato com as secretarias de educação dos municípios e prefeituras e, principalmente, pela proximidade com a universidade na qual somos vinculados, locada na cidade de Rio Grande.

No primeiro momento, buscou-se mapear os projetos esportivos sociais existentes nas cidades acima citadas. Esse levantamento foi realizado através do estabelecimento de contatos com as prefeituras, empresas, instituições e organizações que proponham esse tipo de ação. É importante salientar que após realizado o mapeamento, foram selecionados de acordo com as 
necessidades que a pesquisa estabeleceu alguns dos projetos existentes na região tendo em vista o número expressivo de ações encontradas

Logo em seguida, de posse da identificação dos projetos sociais esportivos existentes nos municípios, fizemos contatos com alguns gestores para que houvesse uma aproximação e em seguida a realização de entrevistas com os proponentes das ações. Diante do expressivo número de projetos e consequentemente de participantes, nesse artigo, optamos por entrevistar um proponente de um projeto social esportivo por cidade escolhida.

Como instrumento para a produção de dados, utilizamos as entrevistas semiestruturadas com os participantes dos projetos sociais esportivos. Essa estratégia pode ser considerada um instrumento de interação e de reciprocidade de quem pergunta e de quem responde, permitindo esclarecimentos, correções, aprofundamentos e novos questionamentos. As entrevistas semiestruturadas, se desenrolam a partir de um esquema básico, porém não aplicado rigidamente, podendo haver adaptações no seu decorrer (LÜDKE e ANDRÉ, 1986, p.34).

Dessa forma, apresentamos a seguir o mapeamento dos projetos sociais esportivos encontrados nesses nove munícipios, bem como as narrativas produzidas pelos proponentes desses projetos e uma breve análise dos discursos e seus efeitos na vida dos sujeitos.

\section{Projetos sociais esportivos: mapeamento no sul do RS}

Como já relatado antes, os projetos sociais esportivos têm ganhado espaço nos últimos anos, principalmente motivados pelos megaeventos esportivos realizados no Brasil como a Copa do Mundo de 2014 e Jogos Olímpicos em 2016. Apresentamos a seguir os achados em termos de políticas sociais esportivas na região sul.

A tabela a seguir foi produzida a partir de dados adquiridos através das prefeituras municipais e secretarias de educação e, em algumas cidades, as secretarias de esporte. Foram fornecidos dados somente dos projetos reconhecidos pela instituição municipal, tendo documentos e registros que validam as ações desenvolvidas nos bairros, espaços públicos e escolas. Porém cabe reconhecer que outras iniciativas sociais, principalmente, de cunho individual, são perceptíveis nos municípios e para este estudo, não menos importantes que aqueles projetos legitimados pelo poder público. Como já exposto anteriormente, optamos em mapear os projetos vinculados as prefeituras pela dificuldade de estabelecer contato e aproximação com as outras iniciativas. 
RELACult - Revista Latino-Americana de Estudos em Cultura e Sociedade

Revista Latinoamericana de Estudios en Cultura y Sociedad | Latin American Journal of Studies in Culture and Society V. 05, no 01, jan-abr. 2019, artigo no 1383 | claec.org/relacult | e-ISSN: 2525-7870

Tabela: Número de Projetos sociais esportivos por munícipio/Projetos escolhidos

\begin{tabular}{|c|c|c|}
\hline Municípios & Número & Projeto participante da pesquisa \\
\hline Arroio Grande & 02 & Centro de Referência Esportiva \\
\hline Canguçu & 04 & Investindo no Futuro \\
\hline Chuí & 03 & Segundo Tempo \\
\hline Pedro Osório & 07 & Educar o Esporte é Formar Cidadão \\
\hline Pelotas & 25 & Atleta do Futuro (SESI) \\
\hline Rio Grande & 21 & Punhos de Esperança \\
\hline São José do Norte & 03 & Pegando Onda \\
\hline São Lourenço do Sul & 05 & Um passe para o Futuro \\
\hline Santa Vitória do Palmar & 06 & Construindo um Futuro \\
\hline
\end{tabular}

Fonte: Dados de Pesquisa

No total, foram localizados 85 (oitenta e cinco) projetos sociais vinculados as práticas esportivas, oriundos das mais variadas iniciativas: públicas, privadas, individuais e comunitárias. Muitos contam com recursos do governo federal através do Ministério do Esporte e de leis de incentivo ao esporte.

Um dos discursos mais evidentes entre as falas dos proponentes dos projetos sociais esportivos está vinculado a violência. Os índices alarmantes ilustram capas de veículos midiáticos, redes sociais, entre outros, alegando que o quadro de violência tem aumentado no estado do Rio Grande do Sul, sobretudo na região sul.

Nesse sentido, a ocupação do tempo ocioso através das práticas esportivas tem buscado amenizar os problemas veiculados a violência, sobretudo por parte de jovens e adolescentes.

"Penso que nosso projeto busca, entre outras coisas, salvar esses meninos do mundo do crime, fazemos de tudo para isso, enquanto eles estão aqui participando, não estão fazendo coisa que não devem na rua, no bairro, na cidade". (Professor A, Projeto Punhos de Esperança).

Pode-se perceber através da fala do professor a preocupação em resgatar os participantes de atividades consideradas perigosas pela sociedade civil. Nesse contexto, o esporte tem papel fundamental em, primeiramente, atrair os jovens e após mantê-los participando das atividades oferecidas.

Uma das condições possíveis para a possibilidade de desvios de conduta por parte de jovens e adolescentes em situação de vulnerabilidade, encontra-se no tempo, que 
invariavelmente é ocupado por um turno através da educação escolar. As políticas sociais têm ganhado a incumbência de ofertar atividades que ocupe o contra turno desses jovens, fazendo assim com que sejam seduzidos por discursos que visam ocupar seus tempos de vida.

"Tirando aqueles que frequentam a escola e ocupam um turno de seu dia, a maioria tem muito tempo ocioso, eles ficam reunidos nas esquinas, conversando, jogando alguma coisa, os adolescentes usando drogas, fumando maconha, aqui isso é mais do que normal". (Professora D, Programa Atleta do Futuro).

Com efeito, outro importante discurso utilizado pelos programas sociais esportivos é o de salvação, independente de que problema vise resolver. A noção de resgate constitui grande parte das políticas sociais, buscando normalizar os sujeitos desviantes. Para isso, são utilizadas regras rígidas de conduta, algo que o esporte, sobretudo de competição ou rendimento, tem como princípio básico de constituição.

"O que mais prezamos no projeto é resgatar as crianças vulneráveis, o esporte tem esse poder de salvar, de mostrar o caminho certo, estamos aqui com esse objetivo, ter esperança que esse quadro pode ser modificado de alguma forma, eles vêm para cá com toda disposição, pelo menos aqui eles cumprem regras e estão socializados". (Professor B, Construindo um Futuro).

Diante da narrativa exposta pelo professor, nos questionamos sobre o poder que o esporte tem de salvar os sujeitos participantes de situações desviantes. Não há como negar que se trata de um discurso que trilha um caminho de hegemonia num país como o Brasil, já que problematizar o papel fundamental do esporte na salvação dos sujeitos, tem se tornado algo praticamente inviável, pelo menos, no que tange o senso comum.

Além disso, pode-se perceber que as modalidades esportivas coletivas predominam os projetos sociais esportivos, sobretudo o futebol, principal manifestação esportiva dos brasileiros. A maioria dos projetos sociais, utilizam a estratégia de oferecer a modalidade com o intuito de se aproximar do público alvo, ou seja, crianças e jovens em situação de risco social. Com isso, visam complementar a Educação Física escolar, de certa forma, reconhecendo uma possível crise pedagógica na disciplina escolar.

"Eles vêm para cá para jogar futebol, gostam de jogar bola, tem professor e ainda participam de campeonatos, tentam 
aproveitar o que tem o projeto, pelo menos muda um pouco o futebol que jogam na rua". (Professor E, Projeto Investindo no Futuro).

Outra forma de atrair participantes para os projetos sociais esportivo é o oferecimento de outros produtos como lanches, vale transporte, eventos e etc. Grande parte das políticas utilizam como alternativa esses serviços advindos de patrocinadores, órgãos públicos e privados e até de recursos dos próprios proponentes.

"O projeto é legal, eles ganham lanche, praticam esporte, dançam, ainda tem a apresentação no final do ano e festinha de natal. Nós professores nos esforçamos para que eles possam se divertir”. (Professor C, Projeto Segundo Tempo).

Para alguns professores, antes mesmo de os participantes aprenderem as modalidades esportivas ou atividades em geral, o principal objetivo dos projetos é a inclusão social e o divertimento, pois acredita-se que para que se mantenham participantes é necessário que desejem estar ocupando aquele espaço.

Em geral, esses discursos têm servido como forma de regular, normalizar e controlar os modos de vida desses sujeitos em condições de vulnerabilidade social. Embora haja consenso sobre a importância dos projetos sociais esportivos, não se pode descartar outras possibilidades de intervenção.

\section{Encaminhamentos}

Diante do objetivo de mapear políticas sociais de esporte na região sul do Rio Grande do Sul e após identificar discursos e seus efeitos através de narrativas por parte dos proponentes, buscamos produzir este material com o intuito de instigar leitores e pesquisadores a realizar novos investimentos a cerca dessa temática.

Entre os discursos enfatizados pelos participantes, pode-se destacar a utilização do esporte como meio para salvação dos sujeitos. Essa promessa ou blasfêmia, visa utilizar um discurso fortemente marcado no meio social com o objetivo de atrair os participantes e seus familiares. O distanciamento da violência e das drogas, também foi identificado como um forte discurso disseminado entre os proponentes das políticas sociais. Além disso, a ocupação 
do tempo ocioso a complementação à Educação Física escolar são importantes ferramentas para a justificativas dos projetos sociais esportivos.

Diante de tal cenário, foi possível perceber que tais políticas, regulam, controlam e normalizam os sujeitos delas participantes, caracterizando novos modos de vida, diferentes formas de ser e estar inserido na sociedade. Por fim, assinalamos que a partir desses efeitos, muito ainda precisa ser repensado nesse tipo de proposta que, por enquanto, parece mais preocupada em normalizar, capturar, orientar e transformar os sujeitos praticantes do esporte social.

\section{Referências bibliográficas}

BOIXADÓS, Marcé et al. Papel de los agentes de socialización en deportistas em edad escolar. Revista de pisicilogia del deporte. Barcelona, v. 7, n. 2, p. 295-310, 1998.

CORREIA, Marcos Miranda. Projetos sociais em educação física, esporte e lazer: reflexões preliminares para uma gestão social. Revista Brasileira de Ciências do Esporte, Campinas, v. 29, n. 3, p. 7-208, maio de 2008.

FRAGA, Alex Branco. Corpo, identidade e bom-mocismo. Belo Horizonte: Autêntica, 2000.

GAWRYSZEWSKI, Bruno. Políticas públicas de lazer para a juventude pobre. Revista movimento, Porto Alegre, v.12, n. 03, p. 265-278, setembro/dezembro de 2006.

GOMES, Maria de Fátima Cabral Marques. Avaliação de políticas sociais e cidadania: pela ultrapassagem do modelo funcionalista clássico. In: SILVA, Maria Osanira. Avaliação de políticas e programas sociais: teoria \& prática. São Paulo: Veras editora, 2001.

GONÇALVES, Maria Alice Rezende. A Vila Olímpica da Verde e Rosa. Rio de Janeiro: Editora FGV, 2003.

GUEDES, Simoni Lahud, DAVIES, Julio D’Angelo, RODRIGUES, Michele Antunes, SANTOS, Rafael Medeiros. Projetos Sociais Esportivos: Notas de pesquisa. XII Encontro Regional de História, Rio de Janeiro, 2006.

LÜDKE, Menga; ANDRÉ, Marli. Pesquisa em Educação: abordagens qualitativas. São Paulo: EDU, 1986.

MACHADO, Paula Xavier et al. O impacto de um projeto de educação pelo esporte no desenvolvimento infantil. v.11 n.1 Campinas jun. 2007

MARSHALL, Thomas.Humprey. Cidadania, classe social e status. Rio de Janeiro: Zahar, 1967. 
MARTINS, César Augusto Ávila. No trabalho de pescadores artesanais a lagoa dos patos vive e dá viva. In: Revista Eletrónica de Geografia e ciências sociales. Universidade de Barcelona, vol. VI, n. 119 (47), ago. 2002.

SALOMÃO, Luís Carlos. Esportes: afeto ou agressão? uma visão revolucionária do mundo dos esportes. São Paulo: Próton, 1987.

SILVA, Maria Ozanira. Avaliação de políticas e programas sociais: aspectos conceituais e metodológicos. In: SILVA, M. O. S. Avaliação de políticas e programas sociais: teoria \& prática. São Paulo: Veras editora, 2001. p. 37 - 93.

SOUZA, Patricia Lânes Araujo de. Projetos sociais e relações de gênero: Apontamento para uma reflexão inicial. In: Salto para o futuro. Ano XVIII Boletim 10 - Junho de 2008. Rio de Janeiro, 2008.

SPOSATI, Aladaíza et. al. Assistência na trajetória das políticas sociais brasileiras. São Paulo: Cortez,1985.

VEIGA-NETO, Alfredo. Foucault e a educação. 2 ed. Belo Horizonte: Autêntica, 2004 